\title{
Evaluation of vernacular landscape attraction for traditional village tourism: A case study of Yongfeng Village in Lanzhou
}

\author{
Zhi-wei Yang ${ }^{1}$, Jihuan Chen ${ }^{1 *}$, Jia-yuan Duan ${ }^{2}$, Ben-teng Liu ${ }^{3}$ \\ ${ }^{1}$ CCTEG Chongqing Engineering (GROUP)Co., Ltd., Chongqing 400010, China; \\ ${ }^{2}$ Arcplus Institute of Shanghai Architectural Design \& Research(Co., Ltd.), Shanghai 200000, China; \\ ${ }^{3}$ School of Design Art, Lanzhou University of Technology, Lanzhou, Gansu Province, 730050, China;
}

\begin{abstract}
In the context of rural revitalization, the benign development of traditional village tourism is of great significance to the implementation of Rural Revitalization Strategy in China. Taking Yongfeng Village in Lanzhou as the research object, this paper discusses the evaluation method of vernacular landscape attraction. Through the research on the internal and external environment and historical culture of Yongfeng village, this paper constructed the rural landscape attraction system and evaluation index. With the help of the effective data of the questionnaire survey, this paper made an empirical calculation of the rural landscape attraction intensity of Yongfeng Village by using the methods of AHP and factor analysis. The results show that: (1) the protection and rational use of historical and cultural resources is the core content to improve the attractiveness of rural tourism landscape; (3) the internal space is the connotation externalization of the attraction of rural landscape, Renovating the historical built-up environment is the material basis for attracting tourists' in-depth experience. Therefore, the effective way to enhance the attraction is to activate and integrate the material and non-material rural landscape resources of traditional villages.
\end{abstract}

\section{Introduction}

In April 2012, the Ministry of housing and urban rural development and other four ministries and commissions jointly promoted the investigation of traditional villages. Since then, the protection and reuse of traditional villages across the country has begun. In October 2017, comrade Xi Jinping made a strategic plan for revitalizing the countryside in the nineteen major reports of the party. Since then, the No.1 central document has directly or indirectly encouraged the development of rural tourism throughout the country. Rural landscape can be formed only after a very long evolution, which bears the characteristics of farming culture different from modern urban and rural areas. In this context, the traditional village has naturally become a high-quality object of rural tourism development. The government and private capital gather to promote the rapid development of traditional village tourism. Although tourism plays a positive role in the revitalization of traditional villages, in practice, it often falls into the dilemma of low-level development because of the homogenization of tourism products, projects and business forms. The over development of eager for quick success and instant benefit leads to the destruction of traditional villages ${ }^{[1-4]}$. Through the tourism perspective to evaluate the local landscape attraction of traditional villages, it can not only clarify the value structure of rural tourism resources, but also guide the reasonable development and effective protection of traditional villages. It is of great significance to the protection of traditional villages and the healthy and sustainable development of rural tourism industry.

Most of the existing studies analyze the composition and evaluation of landscape value from the macro-object of rural settlements, and the research results of different scholars are not the same. Wang Yuncai, Laurent, Jeong, Li Yuqi, etc. ${ }^{[5-8]}$ Chinese and foreign scholars have established rural landscape quality evaluation systems in different areas from aesthetic value, social value and ecological value. Sirakaya, Xie Zhijing and stenseke ${ }^{[9-11]}$ comprehensively evaluate the rural landscape based on tourists' preferences, attitudes and satisfaction, and guide the establishment of a harmonious and progressive rural landscape ecology in terms of society, economy and environment. As far as the traditional village research is concerned, the results are mostly focused on the value analysis and protection evaluation of heritage. For example, Li Qingquan et al. ${ }^{[12]}$ constructed an index system from three aspects of traditional architecture, site selection pattern and intangible cultural heritage to evaluate the value of historical and cultural resources and guide the protection and tourism development of traditional villages. Yang Liguo et al. ${ }^{[13]}$ constructed the index system and evaluation function from the four aspects of authenticity, living attitude, integrity and inheritance, which can better evaluate the protection and utilization status of historical heritage in traditional villages. In addition, some scholars have explored the composition of rural tourism attraction. For example,

*Corresponding author's e-mail: tempiotto@cqmsy.com 
Fairclough $^{[14]}$ discussed the dual tourism attraction of landscape and heritage in Western Europe. Xiao Guangming ${ }^{[15]}$ analyzed the potential attraction of Zhaoqing ancient villages as tourism resources. Shan Fubin et al. ${ }^{[16]}$ constructed a multi-level evaluation method of rural cultural tourism attraction by taking Hetu ala village as an example.

From different angles, there are different ways to construct the element system of tourism attraction. In this paper, the classic theory of tourism area proposed by Liu Binyi et al. ${ }^{[17]}$ is introduced into the research, and the evaluation model of the attraction intensity of traditional village landscape for tourism is established. Taking Yongfeng Village, a traditional Chinese village in Lanzhou City, as an example, this paper further analyzes the intensity structure of landscape attraction, and studies the mechanism of local landscape tourism attraction.

\section{Evaluation Model of Attraction Intensity of Rural Landscape In Traditional Villages}

In this paper, the literature method and expert consultation method are combined to construct the evaluation model of landscape attraction intensity. Firstly, it classifies, distinguishes and selects the complex elements of attraction proposed in the literature. Secondly, referring to the selection criteria of the first to the fifth batch of traditional villages in China, this paper establishes a conceptual model of attraction with full consideration of regional characteristics, and uses Delphi expert consultation method to refine and optimize it. Finally, AHP and factor analysis are used to design a composite evaluation index system to form an evaluation model of traditional village landscape attraction intensity.

\subsection{Construction of landscape attraction system of traditional villages}

\subsubsection{Attraction composition}

According to the definition in the Notice on the Survey of Traditional Villages, traditional villages are those with a long history and rich cultural resources. From the perspective of tourism discipline, traditional villages are a special type of tourist attractions. According to the theory of landscape tourism area, attraction of scenic spots is determined by image, uniqueness, recognition and other factors. Therefore, from the perspective of spatial function, the external production environment of traditional villages, such as mountains and rivers landscape, irrigation and water conservancy, can be divided into settlement external space; The internal living environment of streets, lanes, squares and residential buildings is divided into the internal space of settlements. In addition, the historical culture, artistic aesthetics and experience science carried by the internal and external space are the essence of the traditional village landscape. Based on this, the attraction of local landscape can be divided into three parts: external space attraction, internal space attraction and historical and cultural attraction.

(1) External space attraction. It mainly refers to the attraction of beautiful and scarce rural natural landscape. The overall natural landscape of a village is one of the main factors of attraction. The quality of natural landscape depends on its own characteristics, diversity, and whether it is reasonably protected. If the original natural characteristics of the village can be protected and the environment can be reasonably improved, the farmland scenery has become the biggest attraction of the local scenery, such as the traditional village of Hani terrace, the traditional village of polder around Taihu Lake and so on.

(2) Internal space attraction. It mainly refers to the attraction of artificial landscape environment. It includes not only the overall form of rural settlements, but also local architecture, local flora and fauna, agricultural production and public places. The interior landscape space actively responds to the natural environment and regional climate, and adheres to the Construction Philosophy of adjusting measures to local conditions. The pattern of streets and alleys, the texture of courtyards and the architectural style all contain wise scientific ideas, and precipitate rich historical culture and folk customs.

(3) Historical and cultural attraction. The cultural heritage, tradition, origin and special cultural value of landscape are the main sources of historical and cultural attraction of rural landscape. Rural traditional festivals, folk stories, unique customs and former residences of celebrities are the main manifestations. Cultural differences are the root of the existence of local landscape, so the core of the attraction of local landscape lies in the cultural attributes of traditional villages.

\subsubsection{Establishment of the conceptual model of strength evaluation}

Ko.t.g ${ }^{[18]}$ used the method of combining holistic approach and reductionist approach in tourism evaluation model. Based on this idea, this paper constructs the conceptual model of traditional village landscape attraction intensity evaluation. Based on the analysis of the composition of traditional village landscape attraction, according to the aspects involved in the practice of traditional village protection, this paper summarizes the traditional village landscape attraction model, which is divided into three levels (Figure 1).

First, the first layer and the second layer are determined by holistic approach. The first layer is the criterion layer, which includes three systems: external space attraction, internal space attraction and historical and cultural attraction. The second layer is the factor layer, which includes 13 dimensions such as mountain, water potential, vegetation, farmland, pattern, streets, dwellings, buildings, structures, events, folk customs, skills and seasons. The first four dimensions belong to the content of external space attraction, and the last four dimensions belong to the content of historical and cultural attraction. Secondly, the third layer, the index layer, is determined by the method of reductionist approach. 13 groups of 34 
specific indicators were used to subdivide and describe from the corresponding factor level of each dimension.

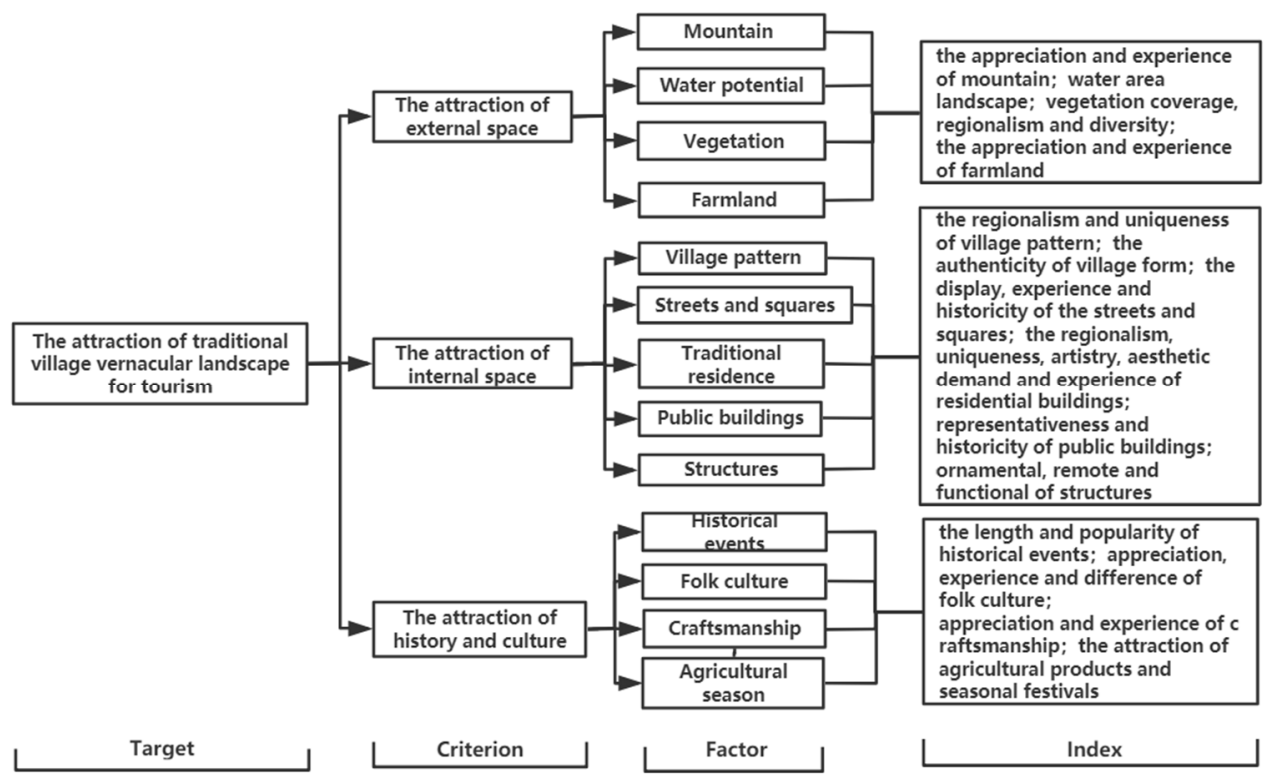

Figure 1. Conceptual model for the attraction of traditional vernacular landscape

\subsubsection{Index selection of strength evaluation}

Each individual indicator in the indicator system reflects a certain aspect of the rural landscape of traditional villages from a specific perspective. From the index layer, the factor layer to the criterion layer, finally take the target layer as the comprehensive expression of the whole research object of rural landscape. The comprehensive evaluation model of rural landscape is constructed by multi-factor linear weighting function method. Follow the principles of systematicness, hierarchy, representativeness, operability and quantification to select the measurement indicators ${ }^{[19]}$. Considering the influencing factors of traditional village landscape attractiveness, further select and determine the specific measurement index under each factor.

In the attraction of external landscape space, the visual impact of landscape space on people is first, followed by experiential. Therefore, from these two aspects, the indicators of mountain, water potential and farmland are determined as ornamental and experiential. Vegetation as a special landscape, vegetation coverage, regionality and diversity are important attractive factors. The attraction of internal landscape space condenses the main living and production space of villagers, which is the space most closely connected with local residents. Regionality, uniqueness, artistry and experience are the important indicators of this level. In the attraction of historical and cultural landscape, the main indicators of this level are remoteness, popularity, appreciation, experience and difference. In order to improve the pertinence and operability of the research, Delphi expert consultation method is used to further correct the index system. Translate some abstract concepts into questions that are easier for the interviewee to understand and answer.

\subsection{Data collection and processing}

From August 1 to 27, 2019, we visited tourism related departments, rural landscape reconstruction related design units and universities twice to investigate the staff who understood the industrial situation and university teachers who carried out relevant research by means of interviews and questionnaires. In the first stage, more than 40 people were pre investigated by open interview, and the index system and weight were improved according to the suggestions put forward in the interview. In the second stage, the formal survey was completed in two steps, with a total of 208 valid questionnaires before and after. First, 140 people were interviewed and 113 questionnaires were completed; Secondly, in order to increase the authenticity and reliability of the data, another 240 questionnaires were issued successively, and 95 valid questionnaires were recovered. The questionnaire mainly investigates the attraction factor intensity of external space attraction, internal space attraction and historical and cultural attraction. The Likert scale was used to set the grade score, and each evaluation index was scored according to the grade rules of "very unimportant 1", "unimportant 2", "generally important 3", " important 4" and "very important 5".

At present, fuzzy comprehensive evaluation method, analytic hierarchy process (AHP), factor analysis method, neural network analysis method and structural equation model are mainly used to analyze the variables affecting the indicators at home and abroad. This study uses spss 22 to obtain the commonness of sample data, and uses AHP and factor analysis to determine the weight of each index in the index system. 


\subsection{Determine index weight}

\subsubsection{Determination of subjective weight by analytic hierarchy process}

Analytic hierarchy process (AHP) can analyze the index system qualitatively and quantitatively. First, according to the importance of the elements, the hierarchical structure of pairwise comparison between the upper and lower levels is established, and then the quantified comparison results are formed into a judgment matrix. Assuming that there are $\mathrm{n}$ elements in the lower layer that are dominated by the upper layer, take two elements $i$ and $j$ each time, and use $e_{i j}$ to represent the ratio of the importance of $\mathrm{i}$ and $\mathrm{j}$ to form a judgment matrix of $\mathrm{n}$ elements $E=$ $\left(e_{i j}\right) n * n\left(e_{i j}>0\right)$. Normalize the elements of each column in the judgment matrix, and the general term of a single element is shown in formula (1) ${ }^{[20]}$. The judgment matrix added and normalized by rows is shown in formula (2) ${ }^{[20]}$.

$$
\begin{gathered}
e \mathrm{ij}={ }^{c i j} / \sum_{i=1}^{n} c \mathrm{ij} \quad(\mathrm{i}, \mathrm{j}=1,2, \ldots, \mathrm{n}) \\
t \mathrm{ij}=\sum_{i=1}^{n} \operatorname{aij} \quad(\mathrm{i}=1,2, \ldots, \mathrm{n})
\end{gathered}
$$

Normalization processing column vector $T=\left(t_{1}\right.$, $\left.t_{2}, \cdots t_{n}\right)$, and let $W_{i}=t_{i} / \sum t_{i}(i=1,2, \cdots, n)$, to obtain the feature vector $\mathrm{W}=\left(\mathrm{w}_{1}, \mathrm{w}_{2}, \cdots \mathrm{w}_{\mathrm{n}}\right)$. Therefore, $\lambda \max =\sum \frac{(\mathrm{E} \cdot \mathrm{W})}{\mathrm{nWi}}$ is the maximum eigenvalue of the matrix E. Calculate the consistency index CI by formula (3) ${ }^{[20]}$ to test the matrix $\mathrm{E}$. When $C I=0, \lambda \max =n$, then the matrix $\mathrm{E}$ is consistent. The larger the value of $\mathrm{Ci}$, the more inconsistent the matrix $\mathrm{E}$ is.

$$
\mathrm{CI}=\frac{\lambda \max -n}{n-1}
$$

\subsubsection{Determining objective weight by factor analysis}

Factor analysis is used to evaluate the objective weight of indicators. First, assume that the observable random index variable $X=\left(X_{1}, X_{2}, \cdots X_{p}\right)$. The index variables are different in order of magnitude and dimension. The incommensurability can be solved by standardizing the data of random variable $\mathrm{x}$. If the mean value is 0 and the variance is 1 , the equation (4) ${ }^{[21] 64} \mathrm{i} S$ obtained.

$$
\begin{gathered}
X_{i}=\left(a_{i 1} f_{1}+a_{i 2} f_{2}+\cdots+a_{i p} f_{p}\right) \\
(\mathrm{i}=1,2, \ldots, \mathrm{p})
\end{gathered}
$$

In this study, principal component analysis was used to calculate the common factor variance of each index. The size of the calculated value represents the influence of each index on the total variation, and the percentage of variance of each common factor in the total is the weight of the index in the whole.

\subsubsection{Determination of compound weight}

Comprehensive subjective weight $w_{1 i}$ and objective weight $w_{2 i}$, using the formula [21] $66 \quad w_{j}=$

\begin{tabular}{|c|c|c|c|c|c|c|}
\hline Target layer A & Criterion layer B & Weight & Factor layer C & Weight & Index layer D & Weight \\
\hline \multirow{14}{*}{$\begin{array}{l}\text { The attraction of } \\
\text { traditional village } \\
\text { vernacular landscape for } \\
\text { tourism }\end{array}$} & \multirow{9}{*}{$\begin{array}{l}\text { B1 The attraction } \\
\text { of External Space }\end{array}$} & \multirow{9}{*}{0.2877} & \multirow{2}{*}{ C1 Mountain } & \multirow{2}{*}{0.1226} & $\begin{array}{l}\text { D1 The contribution of } \\
\text { mountain ornamental }\end{array}$ & 0.0418 \\
\hline & & & & & $\begin{array}{c}\text { D2 The attraction of mountain } \\
\text { experience }\end{array}$ & 0.0809 \\
\hline & & & \multirow{2}{*}{ C2 Water potential } & \multirow{2}{*}{0.0974} & $\begin{array}{l}\text { D3 The attraction of Water } \\
\text { Scenery }\end{array}$ & 0.0579 \\
\hline & & & & & $\begin{array}{l}\text { D4 Entertainment of water } \\
\text { landscape }\end{array}$ & 0.0395 \\
\hline & & & \multirow{3}{*}{ C3 Vegetation } & \multirow{3}{*}{0.0410} & $\begin{array}{c}\text { D5 Contribution of vegetation } \\
\text { coverage }\end{array}$ & 0.0202 \\
\hline & & & & & $\begin{array}{l}\text { D6 The regional attraction of } \\
\text { vegetation }\end{array}$ & 0.0132 \\
\hline & & & & & $\begin{array}{c}\text { D7 The attraction of vegetation } \\
\text { diversity }\end{array}$ & 0.0076 \\
\hline & & & \multirow{2}{*}{ C4 Farmland } & \multirow{2}{*}{0.0267} & $\begin{array}{l}\text { D8 Contribution of farmland } \\
\text { ornamental }\end{array}$ & 0.0087 \\
\hline & & & & & $\begin{array}{l}\text { D9 The attraction of farmland } \\
\text { experience }\end{array}$ & 0.0180 \\
\hline & \multirow{5}{*}{$\begin{array}{l}\text { B2 The attraction } \\
\text { of Internal Space }\end{array}$} & \multirow{5}{*}{0.2561} & \multirow{3}{*}{ C5 Village pattern } & \multirow{3}{*}{0.1052} & $\begin{array}{l}\text { D10 The contribution of } \\
\text { regional village pattern }\end{array}$ & 0.0252 \\
\hline & & & & & $\begin{array}{l}\text { D11 The unique attraction of } \\
\text { village pattern }\end{array}$ & 0.0174 \\
\hline & & & & & $\begin{array}{l}\text { D12 The contribution of } \\
\text { village form authenticity }\end{array}$ & 0.0627 \\
\hline & & & \multirow{2}{*}{$\begin{array}{l}\text { C6 Streets and } \\
\text { squares }\end{array}$} & \multirow{2}{*}{0.0261} & $\begin{array}{c}\text { D13 The historical and cultural } \\
\text { display contribution of streets } \\
\text { and squares }\end{array}$ & 0.0118 \\
\hline & & & & & $\begin{array}{c}\text { D14 The experiential } \\
\text { contribution of streets and } \\
\text { squares }\end{array}$ & 0.0027 \\
\hline
\end{tabular}
$w_{1 j} w_{2 j} / \sum_{j=1}^{n} w_{1 j} w_{2 j}, \quad(j=1,2, \cdots, n)$, the composite weight $w_{j}$ of the index layer can be determined. The specific results are shown in Table 1.

Table1. Evaluation index system of attraction of traditional vernacular landscape 


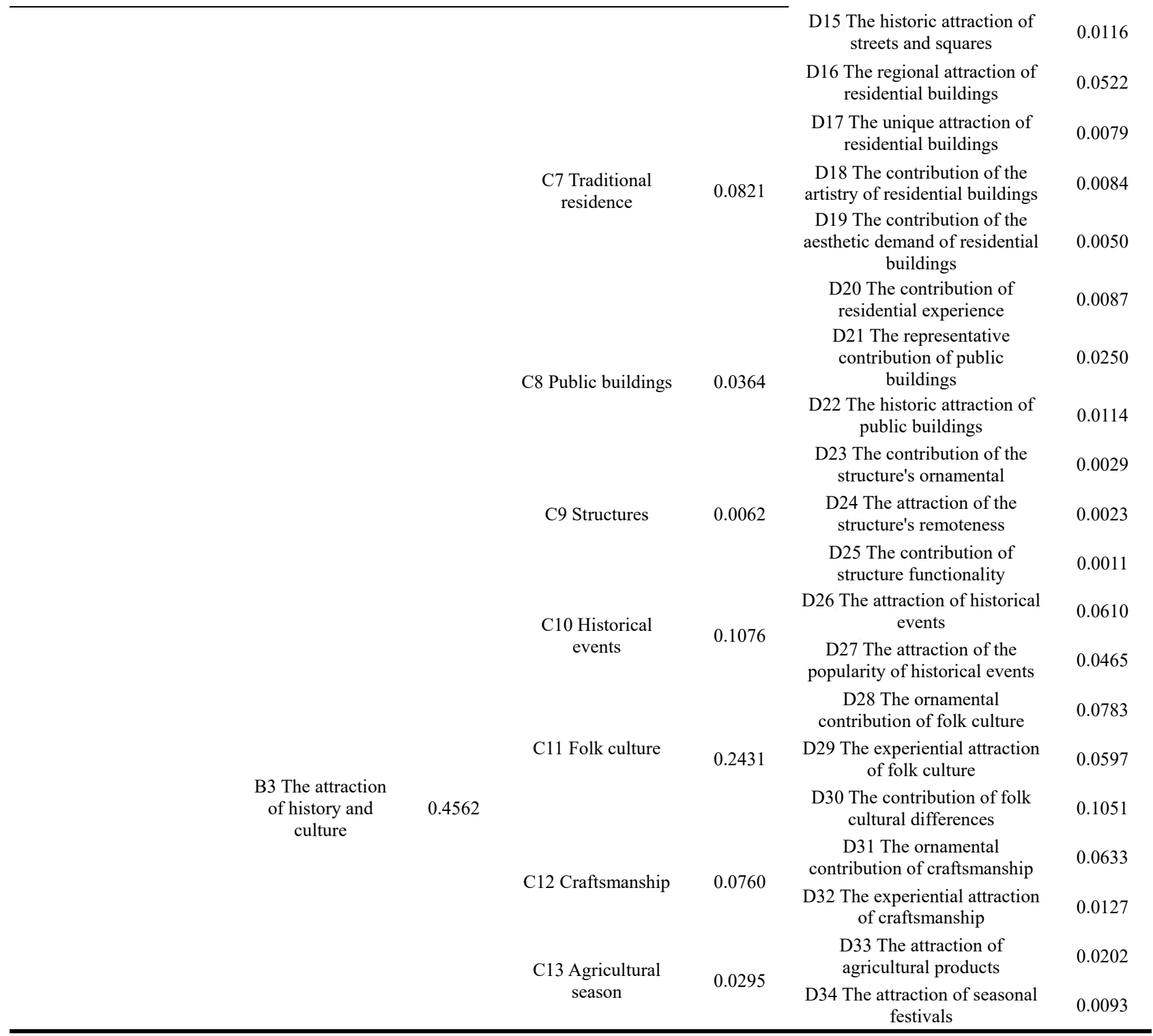

\section{The Empirical Research}

\subsection{Yongfeng Village overview}

Yongfeng Village is located in the east of Jinya Town, Yuzhong County, Lanzhou. The village retains the layout of fort-type village built in Qing Dynasty, and the pattern of "village mountain river field" is complete. In 2016, it was listed in the list of the fourth batch of national traditional villages. It is also a demonstration village for the development of traditional villages in Lanzhou City and an experience base for traditional folk activities in Yuzhong County. The village, with its back on the north mountain and facing the Yuanchuan river, is located on the ancient Silk Road by the Yuanchuan river. It plays an important role in business accommodation and post station in history. It has important historical value. It has accumulated rich traditional material heritage and diversified intangible culture. Since 2017, Yongfeng Village has successively completed the protection planning and design, and the landscape renovation construction of the historical core area. At present, it actively promotes tourism construction under the guidance of the government, and is an important part of cultural tourism resources in Lanzhou. Taking Yongfeng Village as a case study, it has reference significance to study the landscape attraction of traditional villages in Northwest China and even in the whole country.

\subsection{Evaluation function of attraction intensity index}

Using the linear weighting method, this paper estimates the intensity of attraction of traditional village landscape. In (5) and (6) formula ${ }^{[20]}, Z_{i}$ is the intensity index of index $\mathrm{i}$ of index layer, $\lambda_{i}$ is the composite weight of $\mathrm{i}, Y_{i}$ is assigned to likter5 of $\mathrm{i}, Z_{m}$ is the total intensity index of traditional village landscape attraction.

$$
\begin{aligned}
Z_{i} & =\lambda_{i} \times Y_{i} \\
Z_{m} & =\sum Z_{i}
\end{aligned}
$$




\subsection{Result analysis}

\subsubsection{Reliability analysis}

In the study of the attractiveness intensity of rural landscape in Yongfeng Village, in order to ensure the reliability of the analysis data, the reliability analysis of the indicator layer was carried out using formula $(7)^{[20]}$.

$$
\alpha=\frac{k \bar{r}}{1+(\mathrm{k}-1) \bar{r}}, \quad(\alpha \in(0 \sim 1))
$$

In Equation (7), $\mathrm{k}$ is the number of projects evaluated in the study, and $r$ is the mean value of the correlation coefficient of the evaluated projects. The reliability test was conducted by SPSS22, and the results showed that Cronbach's $\alpha$ coefficient value was 0.910 , indicating that the reliability data had inherent consistency and good reliability. We can use index layer data for measurement.

\subsubsection{Sample characteristics analysis}

Table 2 shows the basic demographic characteristics of the sample investigated in this study. 248 valid questionnaires were analyzed, of which the highest proportion was those engaged in tourism performing arts, accounting for $26.18 \%$ of the total. In addition, the majority of the samples were 36-50 years old, accounting for $58.8 \%$ of the total. Most of the people in the sample have received higher education, and $50.21 \%$ of them have received undergraduate education.

Table2. Basic characteristics of sample demography

\begin{tabular}{|c|c|c|c|}
\hline & Research project & Frequency & Percentage/ $(\%)$ \\
\hline \multirow[t]{4}{*}{ Attribute } & University experts and scholars & 35 & 15.02 \\
\hline & Landscape practitioners & 48 & 20.60 \\
\hline & Tourism practitioners & 61 & 26.18 \\
\hline & Farmer & 89 & 38.19 \\
\hline \multirow[t]{4}{*}{ Age } & 20-35 years old & 48 & 20.60 \\
\hline & $36-50$ years old & 137 & 58.80 \\
\hline & $51-65$ years old & 46 & 19.74 \\
\hline & Over 66 years old & 2 & 0.56 \\
\hline \multirow[t]{4}{*}{ Education background } & College degree and below & 36 & 15.45 \\
\hline & bachelor degree & 117 & 50.21 \\
\hline & Master's degree & 49 & 21.03 \\
\hline & Doctoral degree & 31 & 13.31 \\
\hline
\end{tabular}

\subsubsection{Attraction intensity of traditional village vernacular landscape}

According to the index evaluation system and formula (6),

the overall intensity index of local landscape of traditional villages in Yongfeng Village is 3.6243, and the intensity index of each level is shown in Table 3.

Table3. Intensity index of attraction of vernacular landscape for Yongfeng village

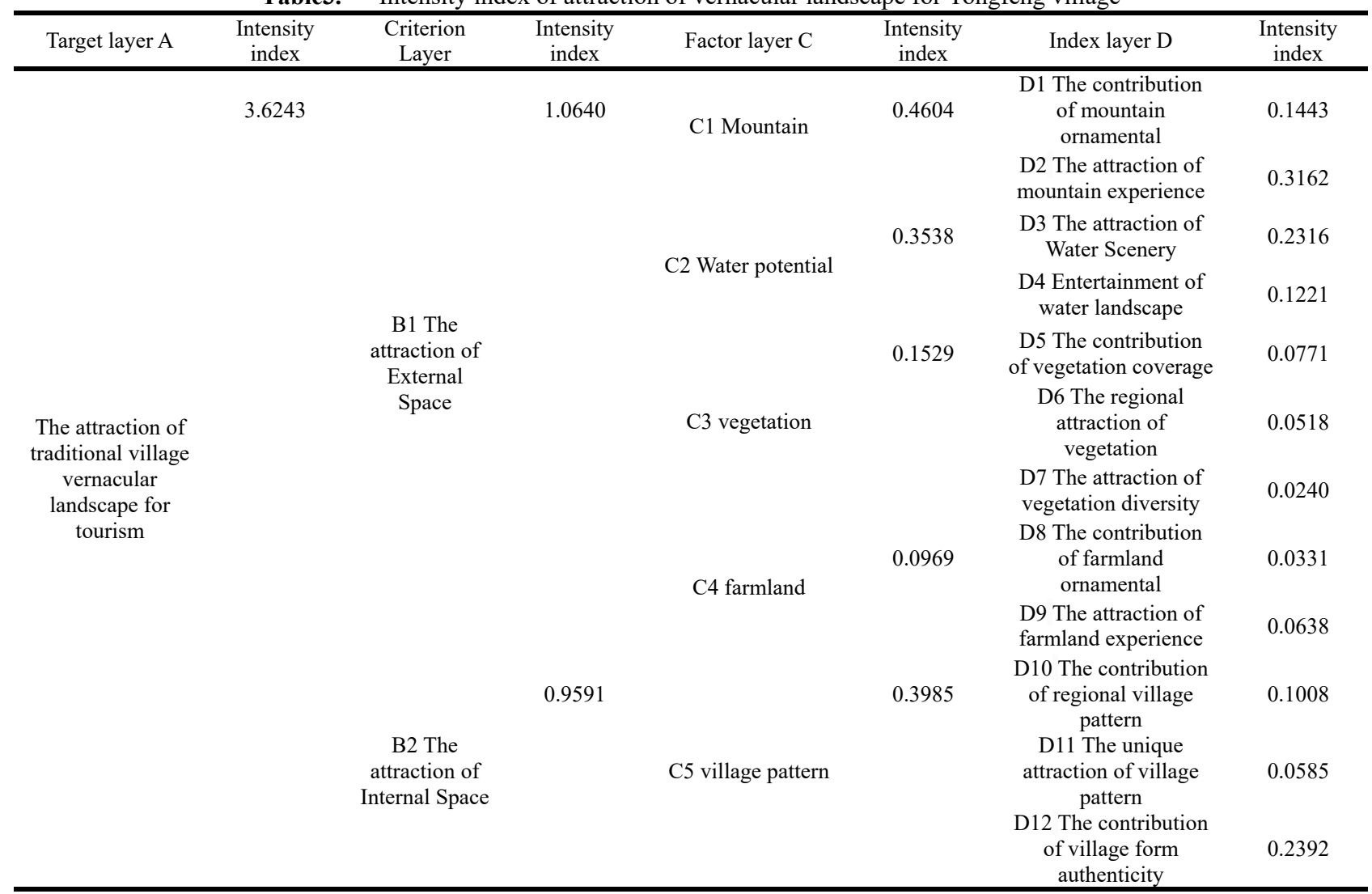




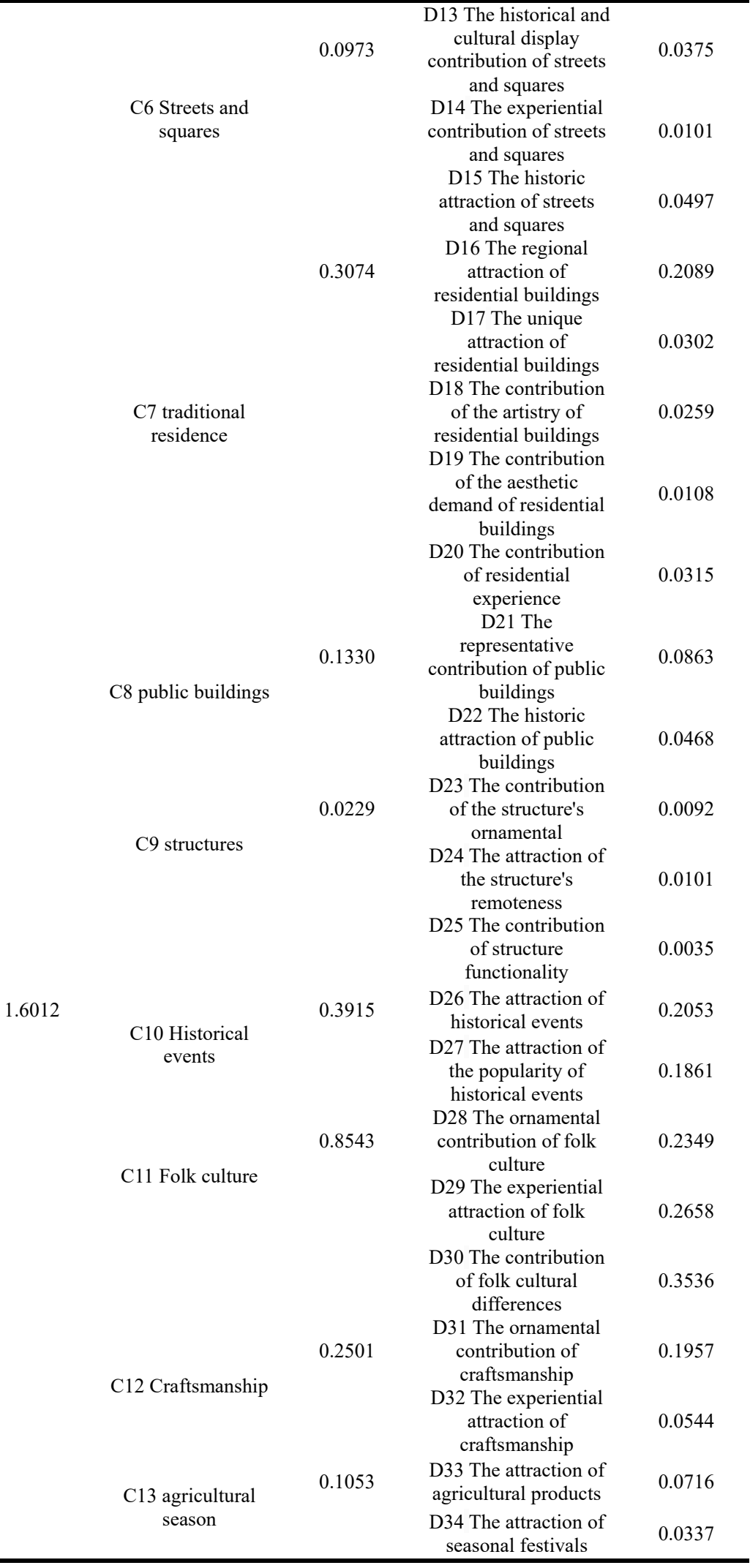

\section{Conclusion and Discussion}

4.1 The historical and cultural attraction reflects the core connotation of the rural landscape, and traditional villages should activate historical landscape resources and extend the cultural context of the landscape 
From the criteria level, compared with the external space attraction, internal space attraction and historical and cultural attraction, the intensity index of historical and cultural attraction (1.6012) ranks first, indicating that historical and cultural attraction is the most important factor affecting the attraction of traditional village landscape. In the process of rural landscape construction, attention should be paid to the living protection of historical and cultural elements such as folk culture, agricultural seasons, and craftsmanship. Among them, the attraction of folk culture (0.8543) ranks first. In the process of developing tourism, we must pay special attention to the excavation of folk culture. The attraction of folk culture comes from cultural differences. Only by fully excavating the differences of folk culture can tourists experience the charm of folk culture and attract more people. In Yongfeng Village, the sacrificial ritual of Qi Yue Guan Shen, the social drama and the traditional hookah production process are combined with the characteristics of traditional culture, and the measures such as adding relevant exchange activities, organizing academic exchanges, carrying out folk art performances, and improving social participation are conducive to the continuation of the landscape context. Historical events (0.3915) are also the focus of public attention. At the beginning, the cognition of villages was largely derived from the cognition of historical celebrities and historical events. There are many historical stories spread in Yongfeng village, such as the General of Jianwei, Golden "Yellow Jacket", Fuyuan Tai Yanfang Association Corps, Princess Wen Cheng went to Tibet and so on. The construction of cultural exhibition hall can better display the long history and culture of Yongfeng Village. Craftsmanship (0.2501) is a traditional village folk art, including wood carving, brick carving and production techniques. The traditional folk houses in Yongfeng Village are not decorated with heavy colors. Using black brick, gray tile, adobe and other materials, the whole village has unique architectural decoration and exquisite carving technology. It is not only a reflection of the historical and social customs and culture, but also the host's yearning and sustenance for a better life, so it should be inherited. Agricultural season (0.1053) is unique to villages. The agricultural products produced in rural areas have always been favored by tourists. Therefore, the construction of agricultural infrastructure should be strengthened to ensure the breeding and planting of agricultural products such as livestock, poultry, fish and shrimp, grain, fruits, and seasonal vegetables. To shape the "one village, one product" agricultural characteristic cultural landscape.

\subsection{The attraction of external space highlights the overall image of the rural landscape. Traditional villages should respect the regional landscape characteristics and improve the external landscape environment}

In terms of the criterion layer, the attraction of external space (1.0640) ranks second. The mountain (0.4604) and water potential $(0.3538)$ in the factor layer are more attractive. This is probably due to the fact that Yongfeng Village is located on the Loess Plateau, surrounded by mountains and rivers. Therefore, the development of the external space of traditional villages should pay attention to the protective use of mountains and water. At the same time, it should be treated differently based on the climate, geology, sunshine, rainfall, vegetation and other natural conditions where the village is located. For example, for Yongfeng Village, the development of the northern mountain mainly adopts the experience development mode, while the development and utilization of the southern water should pay more attention to the beautification of the landscape, and weaken the experience. This is due to the preciousness of water resources in the Northwest. The water environment of the Wanchuan River should be protected as much as possible, and the river course should be improved to make it more ornamental. For the adoption of vegetation (0.1526), attention should be paid to the selection of native vegetation. Vegetation with strong regional characteristics is more attractive. The transition from farming to tourism requires that the landscape experience of farmland (0.0969) be strengthened. The village comes from farmland, which is the material basis and typical life embodiment of the village. Therefore, efforts should be made to explore reasonable ways to promote farmland into effective tourism resources, such as agricultural picking garden, to attract the public to experience farmland life. We should strengthen the combination of agricultural modernization and village tourism industry, optimize and enhance tourism and experience agriculture. Because these natural environments are difficult to feel in modern cities, the external space is more attractive to non-local tourists.

\subsection{The attraction of internal space reflects the concrete style of the rural landscape. Traditional villages should protect the historically built environment and sustainable landscape resources}

From the criterion layer, the attractiveness of internal space (0.9593) ranks third, which is equivalent to the strength of the external space attractiveness index. This indicates that internal space attraction and external space attraction are synergistic driving forces. This is because most of the space inside the village is composed of historical built environment, which is a specific object that tourists can perceive from the nearest distance and has intuitive attraction. In the factor layer, the village pattern (0.3985) and traditional residence (0.3074) are more attractive. On the one hand, it reflects that the village pattern has a strong attraction to the consumer public; on the other hand, it reflects that the traditional residence, as the embodiment of villagers' life, have attracted public attention. Therefore, we should pay attention to the protection of the authenticity of the village pattern. The village pattern is formed through long-term historical evolution. External factors and village pattern should be integrated. Compared with public buildings (0.1330), traditional residence $(0.3074)$ is more attractive to the public. And the public is concerned about the regionality 
and uniqueness of traditional residence. Therefore, in the development of tourism, exploring experiential homestay is the way to make rational use of residential resources. The attraction of public buildings is relatively low. The reason is that the type, scale and quantity of public buildings in villages cannot be compared with those in cities, so it is difficult to impress tourists. Those traditional public buildings that represent the village's clan culture and production activities are more attractive, such as the shuiyanfang and Jin's ancestral hall in Yongfeng Village. The study also found that the attraction of streets and squares $(0.0973)$ is the most easily ignored in tourism development. Because most of the streets in traditional villages are narrow and closed, and there are few open public spaces. It is difficult to excavate the historical connotation and cannot be fully utilized. The attraction of structures varies from village to village. The attraction of structures in Yongfeng village (0.0229) is the lowest among all influencing factors, which may be due to the small number of structures in Yongfeng village.

As the above viewpoints are formed based on the survey and interview of Yongfeng Village, there are still shortcomings in this study: Firstly, the conclusion of this study is limited by external factors. Whether and to what extent the regional differences will affect the research conclusions are unknown, and further investigation is needed. Secondly, the construction of the measurement index system in this research is designed and completed based on the Delphi method and the literature results. Although the strength results have passed the reliability and validity tests, the research index system is complex and the mistakes of factors and indicators are inevitable, which need to be further optimized and improved in future studies. Thirdly, considering that ordinary consumers do not understand the situation of traditional village vernacular landscape, it is difficult to provide valuable answers, so the sample does not include ordinary consumers. The relevant conclusions of this study need to be further tested.

\section{Acknowledgments}

The work described in this paper was fully supported by a grant from the Major State Basic Research Development the National Natural Science Foundation of China (No.51668039).

\section{References}

1. HU Lin-lin, WANG Xue-yong . (2019) Traditional Village Protection and Tourism Development Strategy under the Background of Old and New Kinetic Energy Conversion [J]. Journal of Shandong Agricultural University ( Natural Science Edition ), 50(06): 1071-1075.

2. SUN Lin, DENG Ai-ming, ZHANG Hongchang. (2019) On the Predicament and Solution of Ethnic Traditional Villages' Tourism Activation: A
Case Study of Leishan County, Qiandongnan [J]. Guizhou Ethnic Studies, 40(06): 53-58.

3. LIN Yi, LI Jian. (2019) Research on the Protection and Development of Traditional Villages in Yunnan under the Background of rural revitalization [J]. Journal of Original National Culture, 11(06): 7175.

4. KONG X, WU D, ZHANG J. (2019) The production of traditional village tourism space under the mode of community participation and its influence —_Based on field work in Luxiang ancient village in Dongshan, Suzhou. World Regional Studies, 28(6):156-165.

5. WANG Yun-cai. (2002) Theoritical base and evaluation system of rural landscape assessment in China [J]. JOURNAL OF CENTRAL CHINA NORMAL UNIVERSITY (Nat. Sci.), (03):389-393.

6. Pfund J L, Watts J D, Manuel Boissière, et al. (2011) Understanding and integrating local perceptions of trees and forests into incentives for sustainable landscape management[J]. Environmental Management, 48(2):334-349.

7. Jin Su Jeong, Lorenzo García-Moruno. (2016) The study of building integration into the surrounding rural landscape: Focus on implementation of a Webbased MC-SDSS and its validation by two-way participation[J]. Land Use Policy, 57.

8. LI Yu-qi, LUO Yi-shuang, LI Yan-qiong, PENG Peihao, ZHENG Shao-wei. (2018) Establishment of the Evaluation System for Rural Landscape Quality Based on Analytic Hierarchy Process: Taking Western Sichuan Linpan as an Example. [J]. Journal of Northwest Forestry University, 33(02): 263-268.

9. Hwan-Suk Chris Choi. 92005) Measuring Residents' Attitude toward Sustainable Tourism: Development of Sustainable Tourism Attitude Scale, 43(4):380-394.

10. Xie Zhijing, Bian Xinmin. (2011) Comprehensive Evaluation of Rural Landscape Based on AVC Theory [J]. Jiangsu Agricultural Sciences, 39(02): 266-269.

11. Jones M, Stenseke M. (2011) The European Landscape Convention: Challenges of Participation[J]. Landscape Research, 37(3):1-3.

12. LI Qingquan, WANG Xiaode, ZHANG Xiaogu, ZHONG Xinghua. (2017) The research of traditional village eesources value with the method of index scale AHP and fuzzy comprehensive evaluation[J]. SHANDONG FORESTRY SCIENCE AND TECHNOLOGY, 47(02): 8-15.

13. YANG Li-guo, LONG Hua-lou, LIU Pei-lin 1a, LIU Xiao-lan. (2018) THE PROTECTIONAND ITS EVALUATION SYSTEM OF TRADITIONALVILLAGE:ACASE STUDY OF TRADITIONALVILLAGE IN HUNAN PROVINCE[J]. HUMAN GEOGRAPHY, 33(03): 121-128+151.

14. Graham Fairclough. (2019) Landscape and heritage: ideas from Europe for culturally based solutions in 
rural environments[J]. Journal of Environmental Planning and Management, 62(7).

15. XIAO Guang- ming. (2008) A regional exploiting and management on ancient villages tourism resourses- Take the Zhaoqing for an example [J]. TERRITORY \& NATURAL RESOURCES STUDY, (01): 68-70.

16. SHAN Fubin, ZHOU Jing 1 , LI Xin. (2017) The multi - level evaluation of tourism attraction of rural culture - A case of Hetuala village [J]. Journal of Arid Land Resources and Environment, 31(12): 196-202.

17. LIU Bin-yi, YANG Ming-qi. (2003) The Evaluation Quantization Model of Landscape Area and Tourism Destination-Taking the Overall Planning of Xuanwu Lake Scenic Area as Example[J]. Chinese Landscape Architecture, (06): 63-64+69-70.

18. Tae Gyou Ko. (2003) Development of a tourism sustainability assessment procedure: a conceptual approach[J]. Tourism Management, 26(3).

19. LU Song, CHEN Siyi, Pan Hui. (2010) Preliminary Study on the Assessment of Tourism Sustainability in Ancient Village -Taking World Cultural Heritage Site Hongcun as An Example [J]. Tourism Tribune, 25(01): 17-25.

20. HUANG Wei, MENG Fei, ZHU Zhimin, ZHENG Lifang. (2018) An Empirical Study on the Endogenous Driving Force of Tourism Performing Industry: Taking Zhangjiajie as An Example[J]. Tourism Tribune , 33(06):87-98.

21. XU Lin, ZHAO Ming-xing. (2017) City Home Endowment Service Availability Evaluation System: Based on Factor Analysis and Analytic Hierarchy Process [J]. Journal of Northwest University (Philosophy and Social Sciences Edition), 47(06):6371. 